\title{
Impact of Snow Storms on Habitat and Death of Yunnan Snub-Nosed Monkeys in the Baimaxueshan Nature Reserve, Yunnan, China
}

\author{
Dayong Li, ${ }^{1,2}$ Baoping Ren, ${ }^{1}$ Jie Hu, ${ }^{2}$ Yongsheng Shen, ${ }^{3}$ Xinming He, ${ }^{3}$ \\ Ali Krzton, ${ }^{4}$ and Ming Li ${ }^{1}$ \\ ${ }^{1}$ Key Laboratory of Animal Ecology and Conservation Biology, Institute of Zoology, Chinese Academy of Sciences, \\ Beijing 100101, China \\ ${ }^{2}$ Key Laboratory of Southwest China Wildlife Resources Conservation (Ministry of Education), China West Normal University, \\ Nanchong 637009, China \\ ${ }^{3}$ Baimaxueshan Natural Nature Reserve, Diqing 674400, China \\ ${ }^{4}$ Department of Anthropology, Texas A\&M University, College Station, TX 77843, USA
}

Correspondence should be addressed to Ming Li, lim@ioz.ac.cn

Received 18 September 2012; Accepted 7 October 2012

Academic Editors: M. Cords, B. Crother, and A. Robins

Copyright ( 92012 Dayong Li et al. This is an open access article distributed under the Creative Commons Attribution License, which permits unrestricted use, distribution, and reproduction in any medium, provided the original work is properly cited.

\begin{abstract}
Natural disasters such as snow storms have far-reaching effects on variations in the habitat structure and ecological aspects of nonhuman primates. Yunnan snub-nosed monkeys (Rhinopithecus bieti) inhabit high-altitude forest and endure harsh winters. The effect of heavy snow-storms (January 19 to February 6, 2008) on two large groups of $R$. bieti (Gehuaqing group and Xiangguqing group) inhabiting Samage Forest in the Baimaxueshan Nature Reserve were assessed. Data on habitat damage were collected between March and May 2008 via field line sampling. The snow storms destroyed 237 big trees in the Samage Forest. The destroyed trees were mostly located along the mountain ridge and valley including Abies georgei, Tsuga dumosa, Pinus yunnanensis and Cyclobalanopsis oxyodon. These trees were important for $R$. bieti as they provide a dietary source of lichen that is a critical winter fallback food for this primate species, and consequently food availability for $R$. bieti was reduced. Our results also showed that two juveniles in the Gehuaqing group and three juveniles in the Xiangguqing group were found deceased following the storms. The fact indicates that $R$. biet $i$ is well adapted to high altitude and strongly seasonal habitat might explain its resilience to heavy snow storms.
\end{abstract}

\section{Introduction}

Natural disasters have far-reaching impacts on vegetative biomass, forest structure, food supply, wild animal population demography, and activity in forest ecosystems $[1,2]$. For example, significant losses of tree and shrub species diversity and richness occurred in Wolong National Nature Reserve following the 8.0 magnitude earthquake in 2008 [3]. Earthquakes have also instigated abnormal behaviors and increased activity in nonhuman primates [4]. Fujimoto and Hanamura [5] reported that wild chimpanzees (Pan troglodytes schweinfurthii) displayed scream vocalizations, climbed trees, and stopped grooming and feeding during a high intensity earthquake. Disaster events can also seriously threaten primate populations and social group structure due to their habitat destruction $[6,7]$. For instance, $26 \%$ of chacma baboons (Papio ursinus) died or disappeared after almost 150 days of drought in the Kuiseb River canyon, Namibia [8]. Dittus [9] also reported that group size of toque macaques (Macaca sinica) declined by $15 \%$ because of severe drought. Pavelka et al. [6] found that a population of black howlers (Alouatta pigra) decreased by $88 \%$ during the three and a half years after Hurricane Iris hit southern Belize. One group of golden snub-nosed monkeys (Rhinopithecus roxellana hubeiensis) decreased by 73 individuals after particularly severe snow storms in Shennongiia Nature Reserve, China [7]. 
Yunnan snub-nosed monkeys (Rhinopithecus bieti) live at some of the highest elevations of any nonhuman primate [10]. Currently, only 17 groups of R. bieti totaling almost 2000 individuals remain in the wild [11]. Habitat topography is rugged and steeply sloped, and the climate is extremely harsh; snow covers the ground 4-6 months of the year and the average monthly temperatures in winter are often below freezing [12]. $R$. bieti is a diurnal colobine primate with a diet based on tree lichens and the leaves of angiosperm plants [13]. $75.7 \%$ diets are tree lichens and $10.3 \%$ diets are leaves for R. bieti in winter [14].

Heavy snow storms occurred over large areas of southern and southwestern China from January to February 2008 [15], which also hit the Samage Forest between January 19 and February 6, 2008. The main goals of this study were to (1) assess the damage caused by the snow storms to vegetation for different types of terrains; (2) investigate the dead individual of the two large monkey groups after the snow storms; (3) examine the ecological adaptability of $R$. biet in response to natural disasters.

\section{Methods}

2.1. Study Site. Our study was conducted in the Samage Forest $\left(27^{\circ} 36^{\prime} \mathrm{N}, 99^{\circ} 15^{\prime} \mathrm{E}\right)$ in the Baimaxueshan Nature Reserve, Yunnan Province, China. Two large monkey groups inhabit the area; the Gehuaqing group consisting of 410 individuals [16] and the Xiangguqing group consisting of 480 individuals [17]. The monkeys range from elevations from $2600 \mathrm{~m}$ to $4000 \mathrm{~m}$. The habitat consists of a mosaic of various primary and secondary vegetation zones, including mixed coniferous and deciduous broadleaf forest, highelevation Abies forest, evergreen oak forests, pine forest, and cattle pastures. The site is characterized by marked seasonality in day length, rainfall, and temperature [18]. Annual precipitation can reach $1004 \mathrm{~mm}$, but there is usually a prolonged dry period with almost no precipitation from October to February. The average annual temperature is $14.3^{\circ} \mathrm{C}$. Temperatures can drop to a maximum of $-3.6^{\circ} \mathrm{C}$ in the winter and reach $35.4^{\circ} \mathrm{C}$ in summer at $2,480 \mathrm{~m}$ above sea level [19].

2.2. Data Collection. We investigated habitat damage via field line sampling in the Samage Forest from March 2008 to May 2008. The length of sampling lines was set at $5 \mathrm{~km}$ according to the home range size $\left(>20 \mathrm{~km}^{2}\right.$, see [20]) of the study monkeys. Nine lines were positioned based on different topography: three sampling-lines were set on the ridge from $3500 \mathrm{~m}$ to $4000 \mathrm{~m}$ above sea level, three sampling lines in the valley from $2600 \mathrm{~m}$ to $3100 \mathrm{~m}$ above sea level, and three along the hillside from $3000 \mathrm{~m}$ to $3300 \mathrm{~m}$ above sea level. We recorded the damaged trees within $10 \mathrm{~m}$ each side along the sampling line. Trees (girth $>40 \mathrm{~cm}$ ) were measured and data recorded including species name, girth, tree height, and lichen index. Height and lichen index were estimated by eye. Girth was measured using a forestry tape, and later it has converted to diameter at breast height (DBH). We gave each of the marked trees a lichen-load category, namely, none,

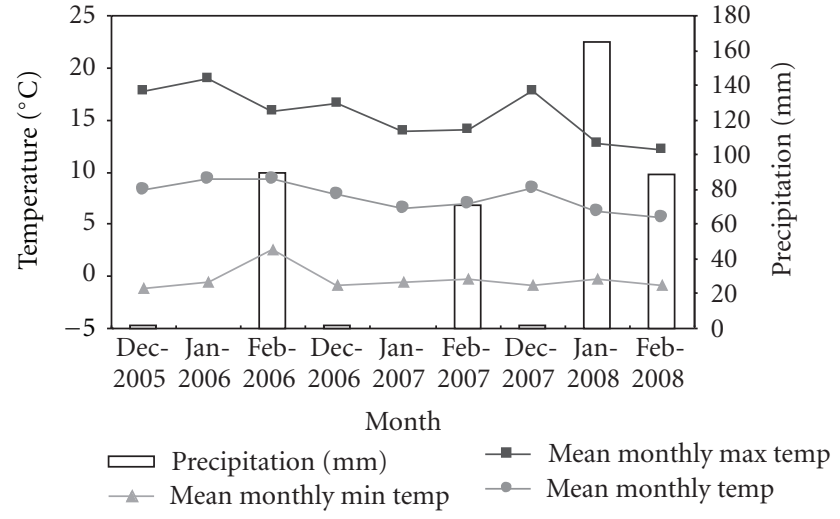

Figure 1: Mean monthly temperature, mean monthly minimum and maximum temperature, and monthly precipitation at Gehuaqing $(2448 \mathrm{~m})$ in winter from December 2005 to February 2008. Precipitation in January and February was mainly in the form of snow in the Samage Forest.

sparse, light, moderate, or heavy. We assigned each category a rank from 0 for none to 4 for heavy to provide a subjective scale for comparison among trees [19]. Meanwhile, dead monkeys were recorded by age and sex, and geographical location, elevation, and vegetation type in the study period.

Climate data were collected at Gehuaqing ( $2448 \mathrm{~m}$ above sea level) in the Samage Forest from 2005 to 2008. From a wireless weather station we measured the amount of precipitation via a professional weather shelter. We also recorded daily minimum and maximum temperatures.

2.3. Data Analysis. We used one-way ANOVA to compare the climate from different years as well as to compare damage habitat at different topographic positions after the snow storms. Descriptive statistics were used to examine dead individuals after the storms. We used SPSS 17.0 and Microsoft Office Excel 2003 to analyze the data. All statistical analyses were two-tailed with the alpha level set at 0.05 .

\section{Results}

3.1. Severity of the Winter of 2007-2008. Each December was dry from 2005 to 2007 (5.0 $\mathrm{mm}$ of precipitation in total) in the Samage Forest (Figure 1). During the study period, most snowfalls occurred in February, and precipitation accumulated to $249.5 \mathrm{~mm}$ at our base camp (2,448 $\mathrm{m}$ above sea level). No snow storms occurred in January 2006 and January 2007. Snow storms occurred in January 2008 and increased the precipitation to $165.3 \mathrm{~mm}$ at our base camp. The precipitation varied significantly in winter across years (one-way ANOVA test: $F_{3,271}=3.825, P=0.023$ ). From 2006 to 2008 snow accumulated to depths of $40 \mathrm{~cm}, 28 \mathrm{~cm}$, and $120 \mathrm{~cm}$ at the end of February at elevations above $3,000 \mathrm{~m}$.

Mean annual temperature was $14.5^{\circ} \mathrm{C}$. Temperatures dropped to extremes of $-3.6^{\circ} \mathrm{C}$ in December. The average temperature was significantly lower in the period between December 2007 and February 2008 than other years (oneway ANOVA test: $\left.F_{3,271}=23.02, P=0.000\right)$ (Figure 1 ). 

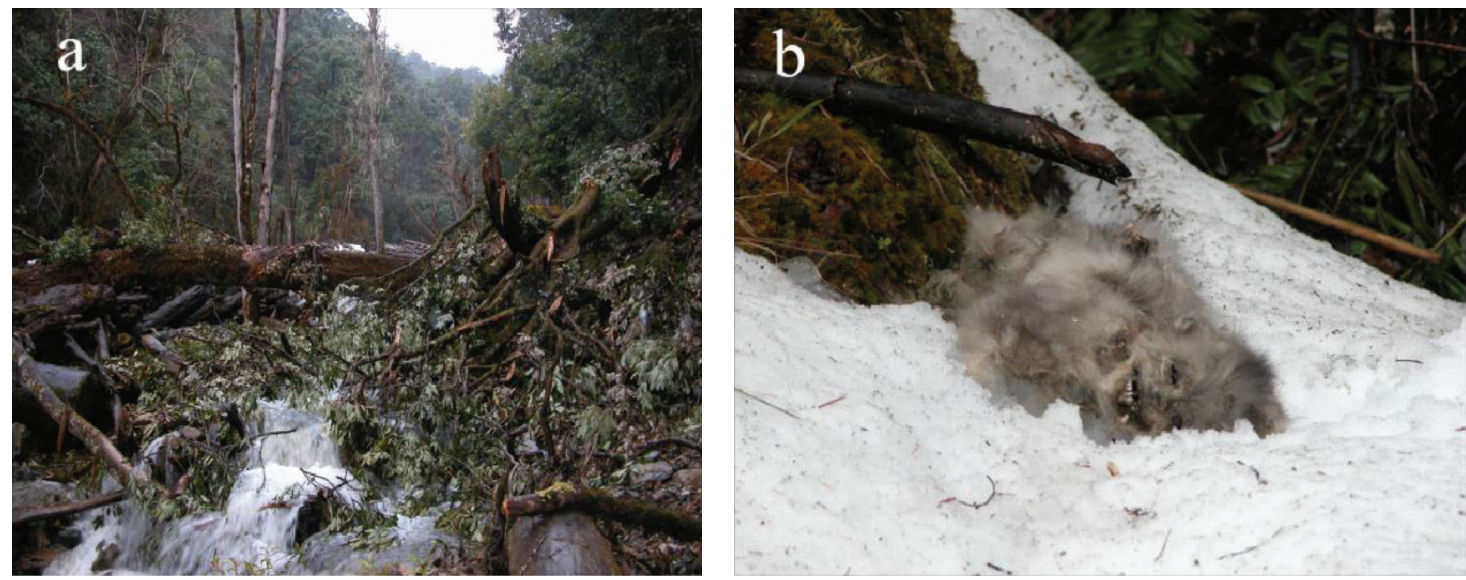

Figure 2: Snow storms destroyed trees and killed several monkeys in early 2008. (a) Fallen trees of Cyclobalanopsis oxyodon at the valley in the Samage Forest. (b) A dead juvenile female at Gehuaqing. (Photograph by Sheng Yongsheng).

TABle 1: Variables of measured trees damaged by the snow storms in different topographic positions at Samage Forest. Data are mean \pm standard deviation.

\begin{tabular}{|c|c|c|c|c|c|}
\hline Topographic position & $\mathrm{DBH}(\mathrm{m})$ & Tree height $(\mathrm{m})$ & Lichen load & No. of fallen trees & No. of tree species \\
\hline On the ridge & $34.2 \pm 9.5$ & $23.6 \pm 5.7$ & $2.5 \pm 0.6$ & 143 & 2 \\
\hline Along the hillside & $47.6 \pm 11.4$ & $26.9 \pm 4.3$ & $1.6 \pm 0.7$ & 29 & 6 \\
\hline In the valley & $58.4 \pm 23.6$ & $24.4 \pm 6.1$ & $0.8 \pm 0.8$ & 65 & 6 \\
\hline Mean & $42.8 \pm 19.1$ & $24.2 \pm 5.7$ & $1.9 \pm 1.0$ & - & - \\
\hline
\end{tabular}

Because temperature decreased with elevation, the temperature within the core area of the band's home range at $3000 \mathrm{~m}$ was about $3^{\circ} \mathrm{C}$ lower than at base camp.

3.2. Habitat Damage. No fallen trees were found after the snow from 2004 to 2007 in the field. However, 237 fallen trees were observed after the snow storms of 2008. Mean DBH of fallen trees destroyed by the storms was $42.8 \pm$ $19.1 \mathrm{~cm}$. The DBH at different topographic positions was highly significant (one-way ANOVA test: $F_{3,237}=60.63, P=$ $0.000)$. The largest fallen tree was in the valley $(58.4 \mathrm{~cm})$ and the smallest on the ridge $(34.3 \mathrm{~cm}$ ) (Table 1$)$. Most fallen trees $(70 \%)$ in the valley were Cyclobalanopsis oxyodon (Figure 2(a)). Mean tree height of fallen trees was $24.2 \pm 5.7 \mathrm{~m}$ and tree height varied significantly with different terrain (one-way ANOVA test: $F_{3,237}=4.078, P=0.018$ ).

Lichen abundance was higher in temperate strata and increased with elevation. Mean lichen load of fallen trees reached 2.5 on the ridge, the highest among the three different topographic positions (one-way ANOVA test: $F_{3,237}$ $=141.28, P=0.000)$.

3.3. Individual Death after the Snow Storms. No dead monkeys were observed from 2004 to 2007 after the snow in the field. However, five juvenile monkeys were found dead at the end of March 2008 in the Samage Forest, two in the Gehuaqing Group and three in the Xiangguqing Group (Figure 2(b)). Among the dead monkeys, four were immature females who died at age two and one was a 5-yearold immature male. All corpses were found severely dry in forests at elevations of $2900 \mathrm{~m}-3200 \mathrm{~m}$.

\section{Discussion}

The heavy snow storm caused extensive damage to the Samage Forest habitat of Yunnan snub-nosed monkeys. The damaged trees species, Abies georgei, Tsuga dumosa, Pinus yunnanensis, and Cyclobalanopsis oxyodon, dominated the forests in the home ranges of two studied monkeys groups. Thus these storms partially destroyed primary forest, which was the main habitat of this monkey species in Samage Forest [19]. Meanwhile, lichen load is high in these damaged big conifer trees, and $R$. bieti prefers to feed on large conifer trees $[13,19]$. The destruction of these food-loaded trees reduced food availability. So, the heavy snow storms thus exerted two powerful pressures on $R$. bieti survival, namely, cold temperatures and food insufficiency. Furthermore, the snow storms destroyed many dominant trees in the study area, thus modifying the forest. As the monkey groups always take a relatively stable ranging path in their home range [21], the damaged forest may cause changes in the ranging behavior of these groups in the following years. Since $R$. biet $i$ only sleeps in the larger trees [22], the destruction of many large trees will very likely influence the selection of sleeping sites by these monkey groups. Thus, the ecological behavior of $R$. bieti may be seriously influenced by the destroyed vegetation type. 
We believe this to be the first documented paper of death of Yunnan snub-nosed monkeys as a result of the effects of heavy snow storms. Since 1998, only five juveniles died in winter because of the heavy snow storms at the beginning of 2008. Comparatively, groups of golden snubnosed monkeys ( $R$. roxellana) in Shennongjia Nature Reserve in central China confronted mass mortality during the same snow storms in 2008, which was thought to relate to the severity of the storms, the presence of rime ice, and the extremely low temperatures [7]. R. bieti is a critically endangered species, which resides at the highest elevation of any extant nonhuman primates [10]. This species lives in extremely low temperatures and heavy snow cover for almost half the year $[20,23]$ and is more adaptable than any other nonhuman primates to a prolonged heavy snow and low temperature. During the worst snow storms, the monkey groups usually move to lower elevations [16]. Lichen forms the major part of the R. bieti diet in the wild [13, 24]. Lichen is present from $2600 \mathrm{~m}$ to $3900 \mathrm{~m}$ elevation in the Samage Forest, with almost all conifer trees and many broadleaf trees covered with lichens at the study site [13]. During the snow storm, lichen becomes a staple fallback food that can meet the essential energy requirements of R. bieti.

No subadult and adults of Rhinopithecus bieti were found dead during the worst snow storm, only juveniles died. Unlike infants, juveniles must get enough food themselves. Compared to adults, however, $R$. bieti juveniles require more energy to grow and resist cold temperature yet the lack of high energy foods maybe causes their death in the heavy snow storms $[7,25]$. Winter in the Samage forest is dry and food abundance is low [13]. Our results showed that the destroyed trees carried higher lichen loads and food deficiency was a real issue for the studied monkeys in winter. Thus if they failed to locate or compete for a range of food sources, they greatly confront the risk of starvation. These scenarios indicate that snow storms can threaten the survival of younger $R$. bieti more than other monkey species after natural disasters $[7,8,26]$.

In summary, heavy snow storms damaged the habitat and affected food availability for $R$. bieti in the Samage Forest. The damaged habitat may inflict long-term effects on the two monkey groups in the area. Due to its adaptability to a cold high-elevation lifestyle, however, the dead individuals of $R$. bieti were not evidently incurred by the heavy snow storms.

\section{Authors' Contribution}

D. Y. Li and B. P. Ren contributed equally to the paper.

\section{Acknowledgments}

This study was funded by the Project of Public Benefit (no. 201104073), the project of National Nature Science Foundation of China (no. 30970442), the State Forestry Administration of China, China Postdoctoral Science Foundation (no. 20110490054), and the China Program of The Nature Conservancy. The authors are grateful to the
Baimaxueshan Nature Reserve for granting a work permit. They also thank four anonymous reviewers for comments on the content of the paper.

\section{References}

[1] R. B. Allen, P. J. Bellingham, and S. K. Wiser, "Immediate damage by an earthquake to a temperate montane forest," Ecology, vol. 80, no. 2, pp. 708-714, 1999.

[2] A. M. Behie and M. S. M. Pavelka, "The short-term effects of a hurricane on the diet and activity of black howlers (Alouatta pigra) in Monkey River, Belize," Folia Primatologica, vol. 76, no. 1, pp. 1-9, 2005.

[3] J. Zhang, V. Hull, W. Xu et al., "Impact of the 2008 Wenchuan earthquake on biodiversity and giant panda habitat in Wolong Nature Reserve, China," Ecological Research, vol. 26, no. 3, pp. 523-531, 2011.

[4] K. A. Snarr, "Seismic activity response as observed in mantled howlers (Alouatta palliata), Cuero y Salado Wildlife Refuge, Honduras," Primates, vol. 46, no. 4, pp. 281-285, 2005.

[5] M. Fujimoto and S. Hanamura, "Responses of wild chimpanzees (Pan troglodytes schweinfurthii) toward seismic aftershocks in the Mahale Mountains National Park, Tanzania," Primates, vol. 49, no. 1, pp. 73-76, 2008.

[6] M. S. M. Pavelka, K. C. McGoogan, and T. S. Steffens, "Population size and characteristics of Alouatta pigra before and after a major hurricane," International Journal of Primatology, vol. 28, no. 4, pp. 919-929, 2007.

[7] Y. Li, X. Liu, M. Liao, J. Yang, and C. B. Stanford, "Characteristics of a group of Hubei golden snub-nosed monkeys (Rhinopithecus roxellana hubeiensis) before and after major snow storms," American Journal of Primatology, vol. 71, no. 6, pp. 523-526, 2009.

[8] W. J. Hamilton, "Demographic consequences of a food and water shortage to desert Chacma Baboons, Papio ursinus," International Journal of Primatology, vol. 6, no. 5, pp. 451-462, 1985.

[9] W. P. J. Dittus, "Group fission among wild toque macaques as a consequence of female resource competition and environmental stress," Animal Behaviour, vol. 36, no. 6, pp. 1626-1645, 1988.

[10] Y. C. Long, R. C. Kirkpatrick, T. Zhong, and L. Xiao, "Status and conservation strategy of the Yunnan snub-nosed monkey," Chinese Biodiversity, vol. 4, pp. 145-152, 1996 (Chinese).

[11] Y. C. Long and R. D. Wu, "Population, home range, conservation status of the Yunnan snub-nosed monkey (Rhinopithecus bieti)," in Abstracts of the China Fusui International Primatological Symposium, pp. 10-11, 2006.

[12] R. C. Kirkpatrick, Ecology and behavior of the yunnan snubnosed langur (Rhinopithecus bieti, Colobinae) [Ph.D. thesis], University of California, Davis, Calif, USA, 1996.

[13] C. C. Grueter, D. Li, B. Ren, F. Wei, Z. Xiang, and C. P. Van Schaik, "Fallback foods of temperate-living primates: a case study on snub-nosed monkeys," American Journal of Physical Anthropology, vol. 140, no. 4, pp. 700-715, 2009.

[14] D. Y. Li, B. P. Ren, X. M. He, G. Hu, B. G. Li, and M. Li, "Diet of Rhinopithecus bieti at xiangguqing in baimaxueshan national nature reserve," Acta Theriologica Sinica, vol. 31, pp. 338-346, 2011 (Chinese).

[15] R. Stone, "Natural disasters: ecologists report huge storm losses in China's forests," Science, vol. 319, no. 5868, pp. 13181319, 2008. 
[16] C. C. Grueter, Determinants of modular societies in snubnosed monkeys (Rhinopithecus bieti) and other Colobines [Ph.D. thesis], University of Zurich, Zurich, Switzerland, 2009.

[17] D. Li, B. Ren, B. Li, and M. Li, "Range expansion as a response to increasing group size in the Yunnan snub-nosed monkey," Folia Primatologica, vol. 81, no. 6, pp. 315-329, 2010.

[18] B. Ren, M. Li, Y. Long, and F. Wei, "Influence of day length, ambient temperature, and seasonality on daily travel distance in the Yunnan snub-nosed monkey at Jinsichang, Yunnan, China," American Journal of Primatology, vol. 71, no. 3, pp. 233-241, 2009.

[19] D. Li, C. C. Grueter, B. Ren et al., "Ranging of Rhinopithecus bieti in the Samage Forest, China. II. Use of land cover types and altitudes," International Journal of Primatology, vol. 29, no. 5, pp. 1147-1173, 2008.

[20] R. C. Kirkpatrick, Y. C. Long, T. Zhong, and L. Xiao, "Social organization and range use in the Yunnan snub-nosed monkey Rhinopithecus bieti," International Journal of Primatology, vol. 19, no. 1, pp. 13-52, 1998.

[21] B. P. Ren, D. Y. Li, P. A. Garber, and M. Li, "Fission-fusion behavior in Yunnan snub-nosed monkeys (Rhinopithecus bieti) in Yunnan, China," International Journal of Primatology, vol. 33, no. 5, pp. 1096-1109, 2012.

[22] D. Y. Li, C. C. Grueter, B. P. Ren et al., "Characteristics of night-time sleeping places selected by golden monkeys (Rhinopithecus bieti) in the Samage Forest, Baima Snow Mountain Nature Reserve, China," Integrative Zoology, vol. 1, pp. 141-152, 2006.

[23] Y. Long, C. R. Kirkpatrick, Zhongtai, and Xiaolin, "Report on the distribution, population, and ecology of the yunnan snubnosed monkey (Rhinopithecus bieti)," Primates, vol. 35, no. 2, pp. 241-250, 1994.

[24] Z. F. Xiang, S. Huo, W. Xiao, R. C. Quan, and C. C. Grueter, "Diet and feeding behavior of Rhinopithecus bieti at Xiaochangdu, Tibet: adaptations to a marginal environment," American Journal of Primatology, vol. 69, no. 10, pp. 11411158, 2007.

[25] C. H. Janson and C. P. van Schaik, "Ecological risk aversion in juvenile primates: slow and steady wins the race," in Juvenile Primates: Life History, Development, and Behavior, M. E. Pereira and L. A. Fairbanks, Eds., pp. 57-74, Oxford University Press, New York, NY, USA, 1993.

[26] L. Gould, R. W. Sussman, and M. L. Sauther, "Natural disasters and primate populations: the effects of a 2-year drought on a naturally occurring population of ring-tailed lemurs (Lemur catta) in southwestern Madagascar," International Journal of Primatology, vol. 20, no. 1, pp. 69-84, 1999. 

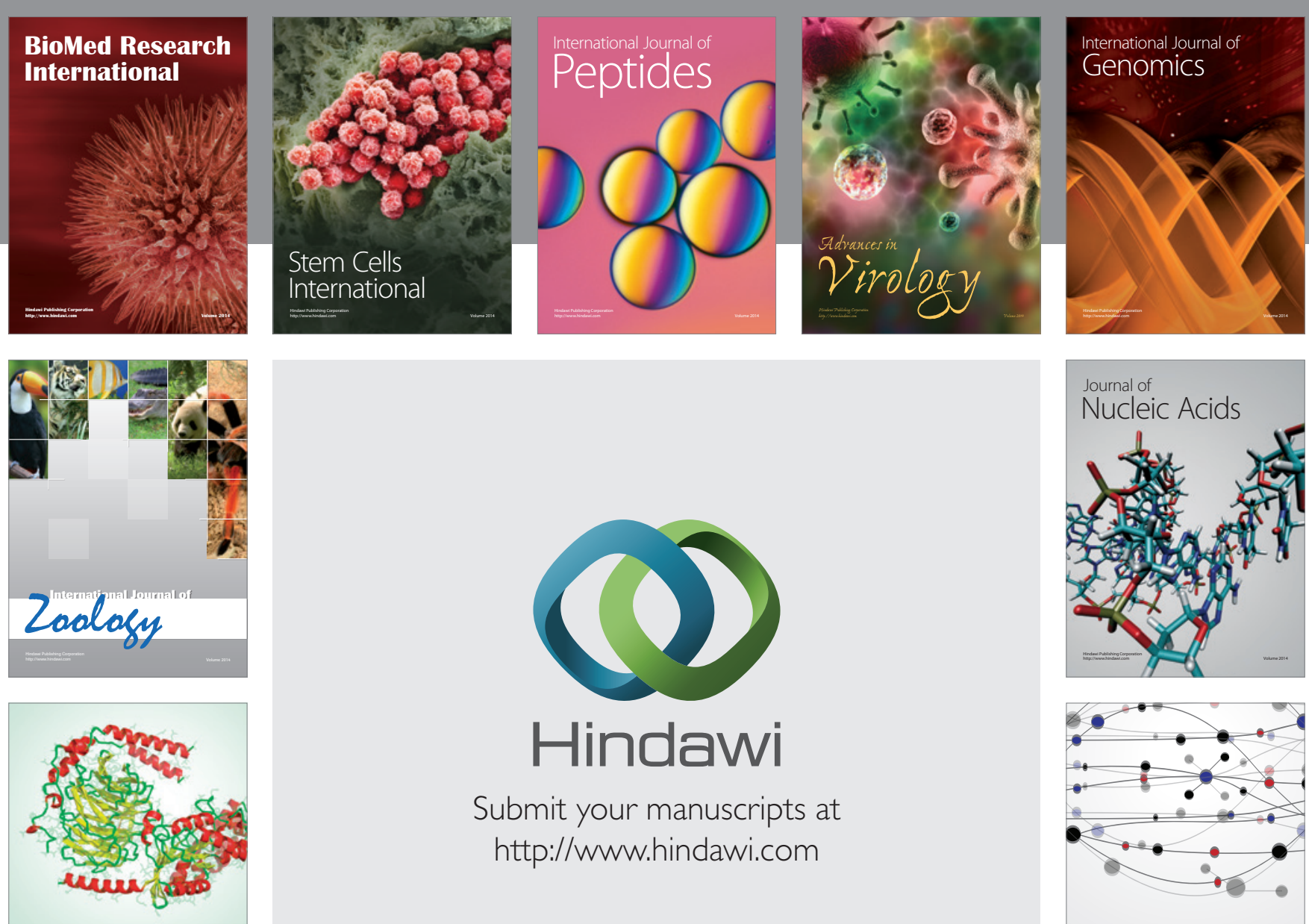

Submit your manuscripts at

http://www.hindawi.com

Signal ${ }^{\text {Jumal }}$ Transduction
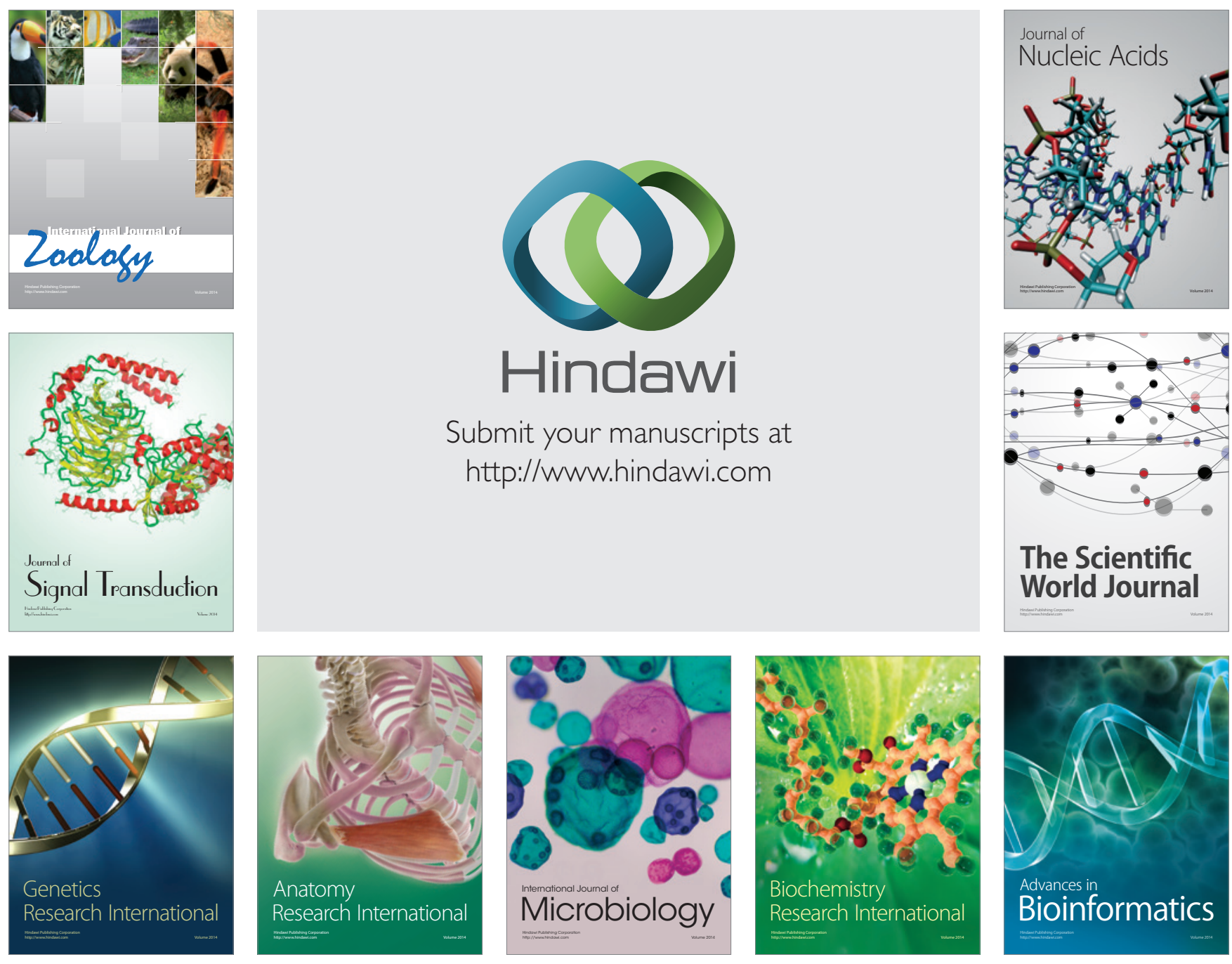

The Scientific World Journal
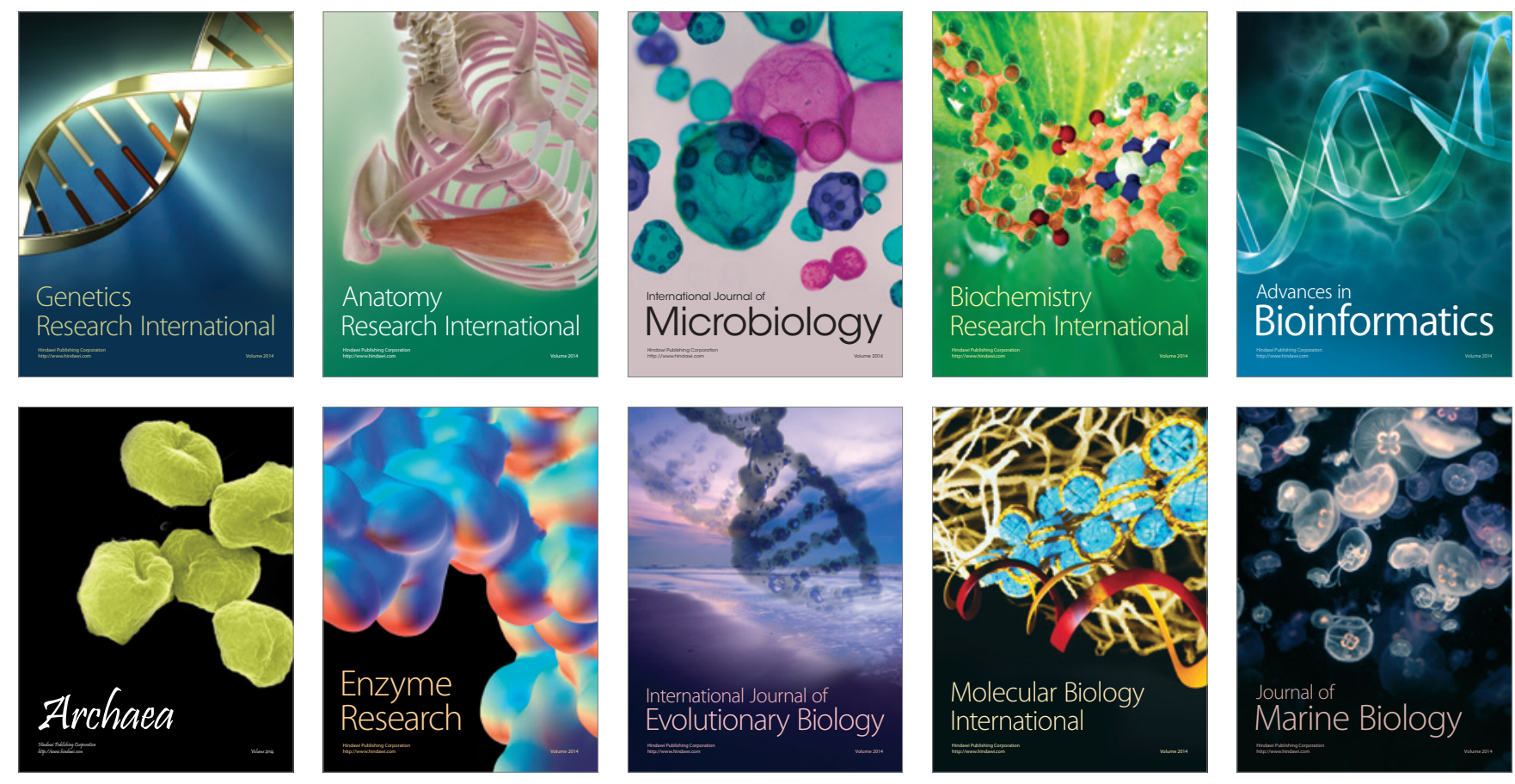